\title{
Analysis of positioning of wayside charging stations for hybrid locomotive consists in heavy haul train operations
}

\author{
Shah Ahmad ${ }^{1}$ (D) Maksym Spiryagin ${ }^{1} \cdot$ Colin Cole $^{1} \cdot$ Qing Wu $^{1} \cdot$ Peter Wolfs $^{1} \cdot$ \\ Chris Bosomworth ${ }^{1}$
}

Received: 25 March 2021/Revised: 10 May 2021/Accepted: 14 May 2021/Published online: 25 July 2021

(C) The Author(s) 2021

\begin{abstract}
Hybrid locomotive concepts have been considered as a step towards converting the railway industry into a green transport mode. One of the challenges in integrating a hybrid locomotive in the train consist is that the battery pack in the locomotive needs to be recharged during a long-haul trip which requires stopping of the train. A typical battery pack requires about $1 \mathrm{~h}$ to recharge which is unacceptable. With the improvement in the charging system, it is now possible that the same capacity battery pack could be recharged in 10-12 min which can be a competitive option for the railway companies. This paper proposes a method based on simulation to evaluate the positioning of charging stations on a train network. A typical example of a heavy haul train operation hauled by diesel-electric and hybrid locomotives is used to demonstrate the method by using simulation softwares. The result of the simulation study show that the method developed in this paper can be used to evaluate the state of charge (SoC) status of a hybrid locomotive along the track. It is also shown that the SoC status obtained by the simulation method can be further used to assess the positions of charging stations along the track at the design stage.
\end{abstract}

Keywords Hybrid locomotive - Wayside charging station · Co-simulation $\cdot$ Multibody Simulation

Shah Ahmad

s.ahmad@cqu.edu.au

1 Centre for Railway Engineering, Central Queensland University, Rockhampton, QLD, Australia

\section{Introduction}

A hybrid vehicle system incorporates an auxiliary electrical power system that can add additional energy during acceleration, hill climbing, etc. The hybrid system is also useful where frequent stopping and slow speed operation is needed such as in city traffic, where only the electrical system can be utilised to reduce fuel consumption. In railway applications, the availability of a large space for the energy storage system (ESS) attracts an alternative operation mode where significant power can be shared equally between the diesel and electric mode, known as a dual-mode hybrid locomotive [1].

The use of a high capacity ESS is particularly encouraged in train applications to capture some of the energy from the dynamic braking application. The electrical energy that is produced during the dynamic braking of a train is wasted as heat unless it is being utilised by other means. The recovery of dynamic braking energy to use in driving the vehicle has been considered a way of fuel-saving since the 1970s. The Federal Railroad Administration (FRA) assessed the feasibility of a dual-mode locomotive in 1979 [2]. The study concluded that the electric mode of dual-mode locomotives provides higher power than the diesel mode, and as such would provide cost-advantages to railroads on ruling grade tracks. A specific recommendation was to electrify the ruling grades to allow the operation of a dual-mode locomotive on the ruling grades. It is understood that the ESS option was not considered in [2] as that technology was not fully developed at that time.

Electrification of the full track network of a heavy haul operation might not be attractive where a limited number of trains operate on such a track and savings in energy may not be appealing compared to the cost of electrification infrastructure for the entire network. An alternative to the 
electrification of the entire railway network is the ESS on vehicles that can be recharged at wayside charging stations.

In the case of recharging during travelling over the route, the recharging time would need to be competitive with the refuelling experience in the automotive field, i.e. 8-10 min. With the progress in battery technology, it is now possible to use a rapid, fast, or ultra-fast charger to reduce the charging time of an ESS. The charging time can be evaluated from the $\mathrm{C}$ rate of the charger which is defined as the time required to charge an ' $\mathrm{X}$ ' $\mathrm{Ah}$ battery system using a charging current of ' $\mathrm{X}$ ' $\mathrm{A}$ in $1 \mathrm{~h}$. As an example, a $5 \mathrm{MWh}$ battery system would be charged in $1 \mathrm{~h}$ by a $1 \mathrm{C}$ charger that would have a charging capacity of $5 \mathrm{MW} / \mathrm{h}$ (with charging current of $1886 \mathrm{~A}$ at a voltage of $2650 \mathrm{~V}$ ). Based on charging rate, chargers can be of different types-slow chargers $(0.1 \mathrm{C})$, rapid chargers $(0.3-0.5 \mathrm{C})$, fast chargers (1 C), and ultra-fast chargers (1-10 C) [3]. An ultra-fast charger is capable of charging up to 10 times faster than a fast charger. However, it needs to be noted that a higher charging rate would put more stress on the battery system and the battery capable of sustaining a high capacity of charging would be expensive. Another important fact is that the ultra-charging option applies to a $70 \%$ state of charge (SoC) only. In addition to that, the rapid charging method increases deposits of lithium-ion on the negative electrode (lithium plating) due to the large current application [4]. It is possible to allow faster charging by modification of the battery system such as the use of a thinner electrode, increasing electrode surface area, and increasing the temperature of the system to a specific value before charging to decrease lithium plating [4]. However, such modification would increase the cost of the system.

Battery life is an important consideration while choosing the charging and discharging cycles. Nelson [1] reported that the battery should be operated at a nominal 50\% SoC level so that it can be operated between $20 \%$ and $80 \%$ SoC to avoid deep discharge and overcharge when subject to a large current surge. It is recommended that hybrid locomotives should be operated at a 30\%-70\% SoC limit [1]. Running at around $50 \%$ capacity limit of the battery would require a battery capacity of double that required by the hybrid locomotive. Considering the locomotive design aspects, the charging and discharging cycle concept described in [1] can be transformed as shown in Fig. 1.

Evaluation of the state of charge (SoC) in a hybrid locomotive by a simulation approach has been developed in previous studies [5-7]. Generally, three different simulation environments are used to evaluate necessary performance parameters. Train simulations are used to evaluate the train operation data such as speed profiles, notch conditions, and coupler force components. The wheel-rail contact and mechanical model of the vehicle are modelled in multibody software. The electrical parts of the model, i.e. power source, power sink, power, and SoC component, were modelled as code generation in a programme such as Simulink. Cosimulation can be performed between longitudinal train simulation (LTS) and multibody simulation (MBS) [5, 6] and between MBS and Simulink [7]. The co-simulation technique allows the transfer of data between two environments at each time step or at a given condition provided in the code. Co-simulation can also be performed by manual export and import of data between two environments when back and forth transfer of data is not required.

In this paper, a four-step method and a case study are presented on the simulation tools developed in [5-7] to demonstrate the analysis of the positioning of charging stations based on SoC assessment.

\section{Methodology}

The methodology to assess the positions of wayside charging stations on a track network is shown in Fig. 2. The main steps are given as follows:

Step 1 Selection of track geometry, trip conditions, train configurations, and operational scenario of a route.

Step 2 LTS on the selected conditions in step 1 to evaluate train speed and notch corresponding to track positions.

Step $3 \mathrm{MBS}$ of the hybrid locomotive model using the generated train speed and notch conditions along the route. The mechanical part (all bodies, suspension elements, wheel-rail contact) of the locomotive to be modelled in a multibody simulation software while the electrical part (battery system, traction control systems, and inverters) of the locomotive to be modelled in a code-generated platform such as Simulink (Fig. 3). The mechanical and electrical part of the model is connected via a co-simulation server that allows the transfer of data between these two software environments at every time step. The locomotive speed, the angular speed of the traction motor, the angular speed of the wheelsets, the notch, and the dynamic brake (DB) status obtained in MBS are transferred to Simulink. The calculated power and SoC status in the Simulink model is transferred from Simulink to MBS.

Step 4 Running the MBS to obtain the outcome of dynamic parameters. Based on the required minimum charge status of a battery, it is important to recharge a battery at a $40 \%$ SoC level. Hence, the required charging station would need to be at a place where the SoC reaches not less than $40 \%$.

\section{Case study}

A hypothetical train and track combination has been used to demonstrate the method proposed in this paper. It is assumed that the train would travel from port to mine in the 


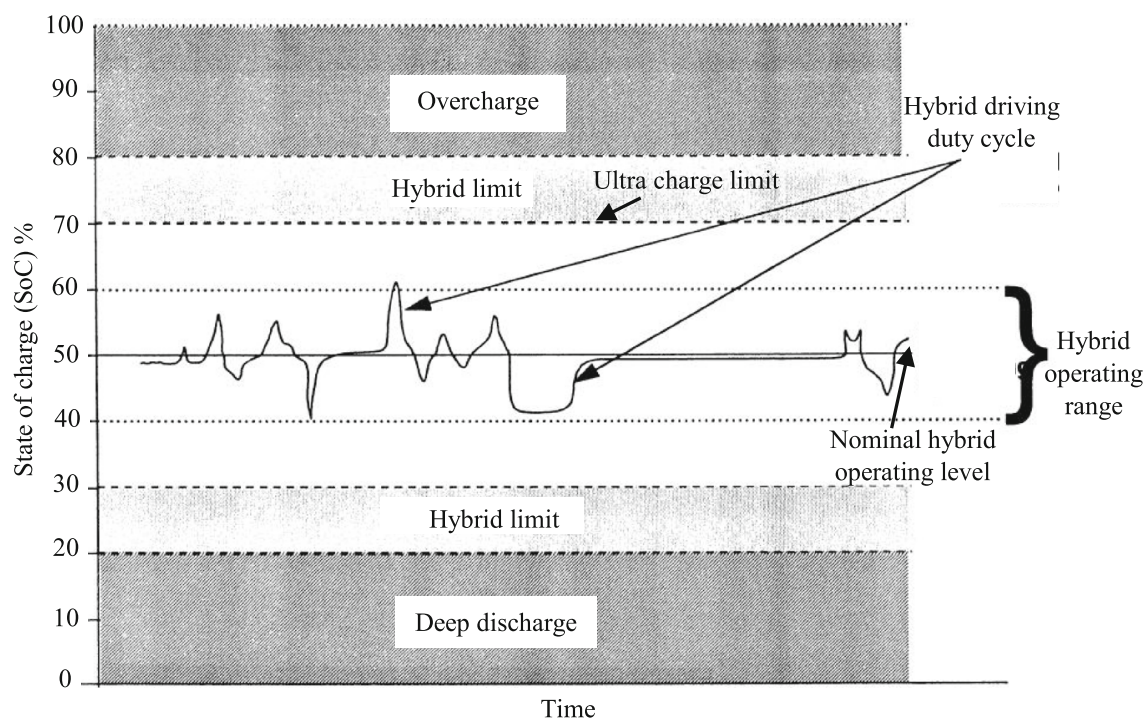

Fig. 1 Recommended state of charge limits for battery operation in hybrid locomotives [1]

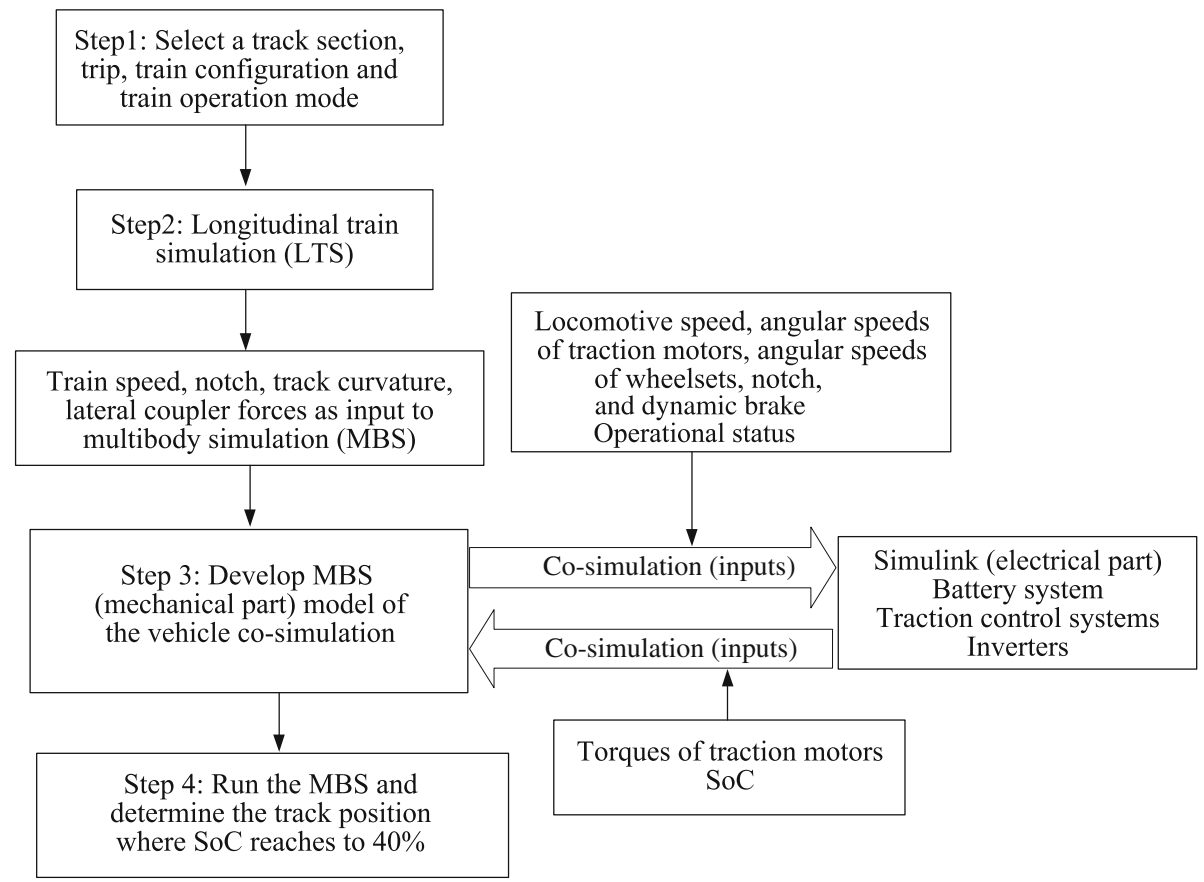

Fig. 2 Methodology to evaluate SoC status of a hybrid locomotive using a co-simulation approach

empty condition and mine to port in the loaded condition. A gradient track and a speed restriction file were chosen to induce instances of the use of DB during the running of the train on the track. Two trip options were considered:
Trip 1 Loaded trains start with $100 \%$ SoC from the mine and empty trains start with the available $\mathrm{SoC}$ at the end of the first leg of the trip. Two cases were simulated in MBS: 


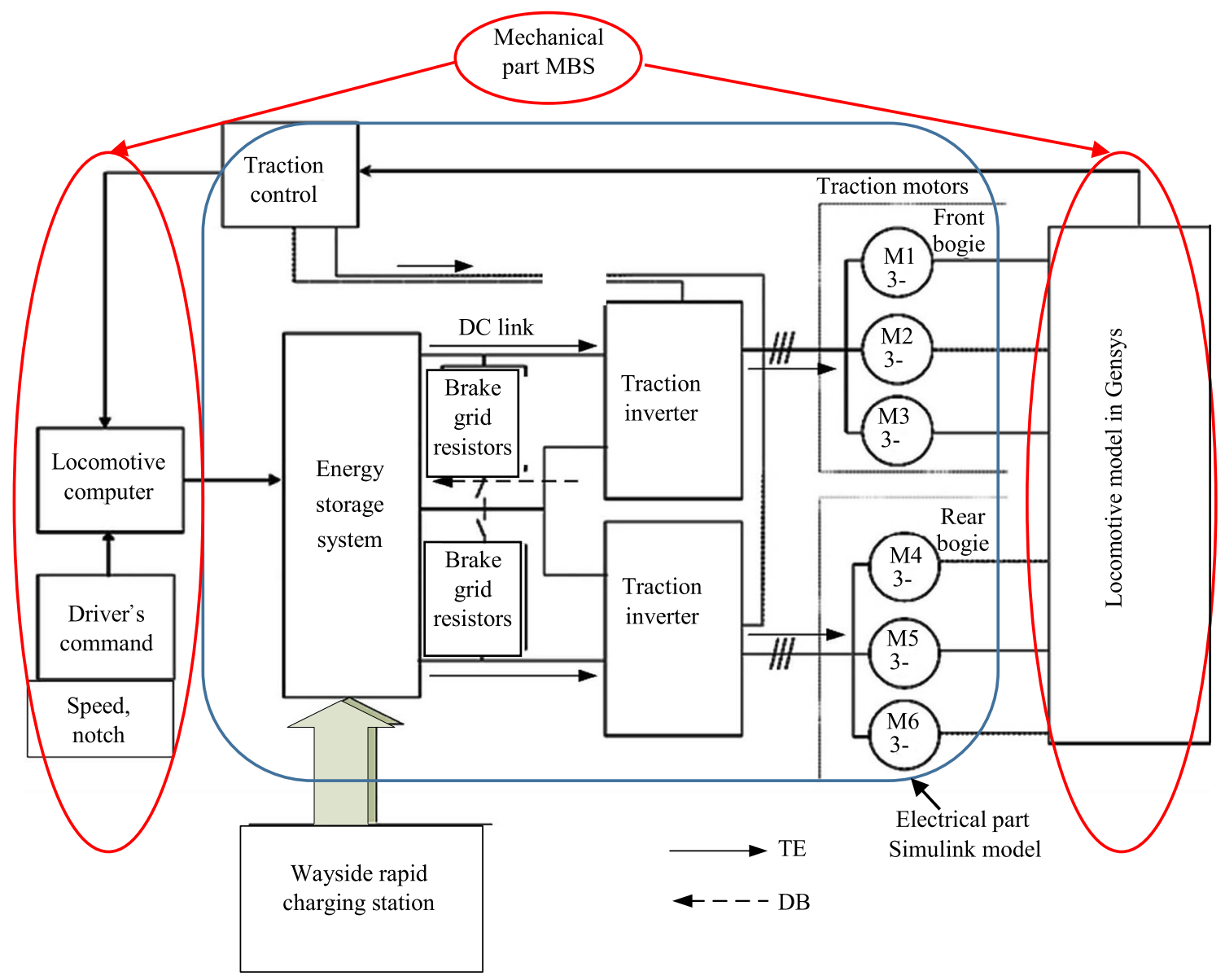

Fig. 3 Modelling of a hybrid locomotive

Case 1 Loaded, mine to port, starting with $100 \%$ SoC.

Case 2 Empty, port to mine, starting with the remaining SoC in case 1.

Trip 2 Empty trains start with 100\% SoC from the port and loaded trains start with the available $\mathrm{SoC}$ at the end of the first leg of the trip. Two cases were simulated in MBS:

Case 3 Empty, port to mine, starting with $100 \%$ SoC.

Case 4 Loaded, mine to port, starting with the remaining SoC in case 3.

\subsection{Track data}

A straight track section of $130 \mathrm{~km}$ was chosen for the study (Fig. 4). Some gradients were added to the track. A speed board dataset was chosen to guide the train operation. Due to steep gradients, the track speed was limited to $50 \mathrm{~km} / \mathrm{h}$ for most of the track section.

\subsection{Train data}

Following the methodology previously described, train operations were performed in an in-house train simulation software called CRELTS. Trains were constituted as 2 locomotives and 100 wagons. Of the two locomotives, one is a diesel-electric (GT46C-Ace type) and the other is a hybrid type (a modified version of GT46C-Ace type). The mass of the locomotives was chosen as $136 \mathrm{t}$ in the train simulation. The maximum traction effort (TE) and the maximum DB effort were chosen as 600 and $325 \mathrm{kN}$, respectively (Figs. 5, 6). The TE and DB effort were equally distributed over 8 notch settings. The wagons were chosen as a container carrying type having a tare mass of $18 \mathrm{t}$ and loaded mass of $90 \mathrm{t}$.

\subsection{Train operation data}

The train operations were simulated using a fuzzy controller that follows a speed profile and makes necessary throttle adjustments to follow the given speed board data along the track (Fig. 7a). The generated speed can vary 


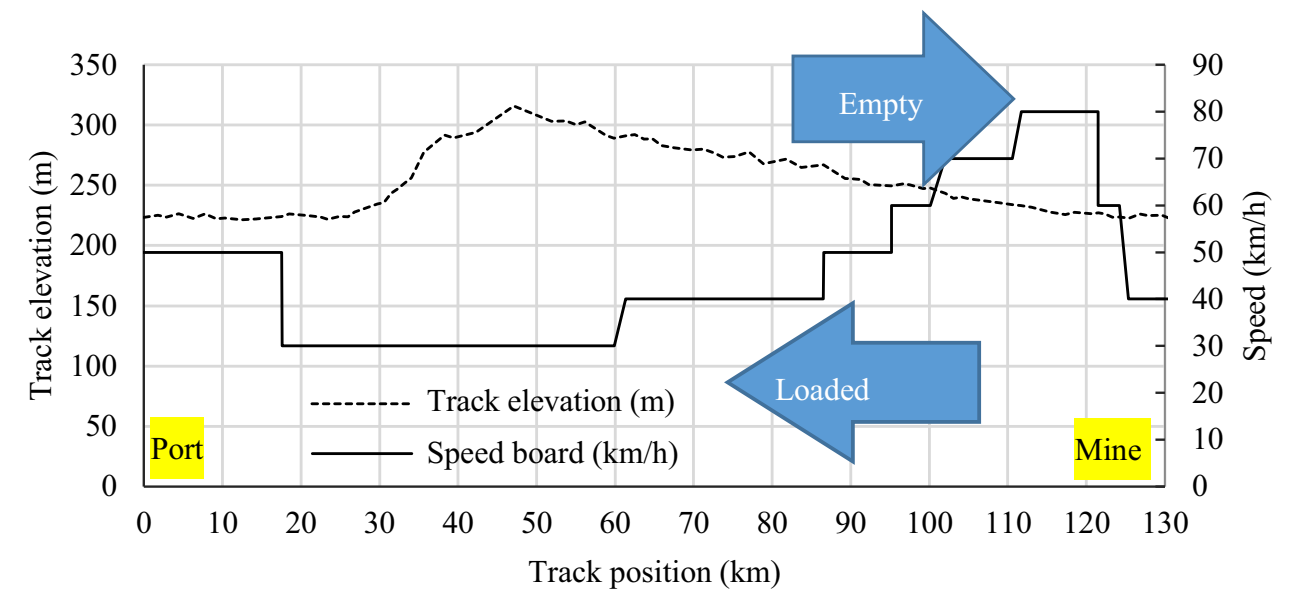

Fig. 4 Track file of a straight track section

from the speed board limit data based on the chosen characteristics in the fuzzy logic controller. It is understood that a variation in following speed boards would exist among driving strategies that have not been added in this paper.

The locomotive throttle positions in Fig. 7b were specified as the percentage of full throttle (notch 8). Negative throttle indicates that the dynamic brake has been applied. In this train simulation, it is assumed that only DB would be applied to restrict the speed to the chosen limits. It can be noted that the speed also depends on the load of the train. On a descending grade, the loaded train tends to generate a higher speed compared to an empty train due to gravity. As an example, the speed on the loaded train started to increase significantly at a track location of about $30 \mathrm{~km}$ and reaches $52 \mathrm{~km} / \mathrm{h}$ from $30 \mathrm{~km} / \mathrm{h}$ in about a $2 \mathrm{~km}$ distance before being reduced to $30 \mathrm{~km} / \mathrm{h}$ by the application of full DB force for a long distance of $5 \mathrm{~km}$ (Fig. 7). In

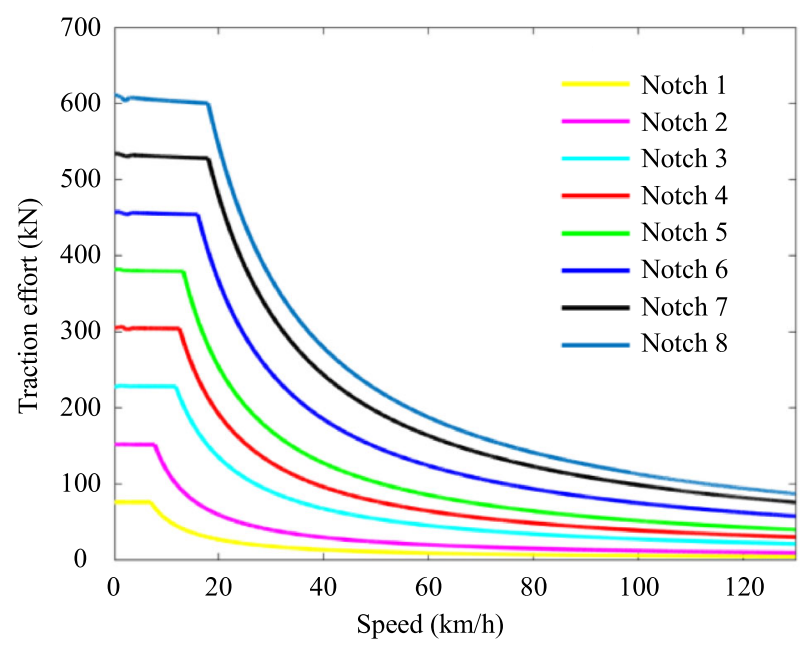

Fig. 5 Traction effort characteristics for GT46C-ACe locomotive [6]

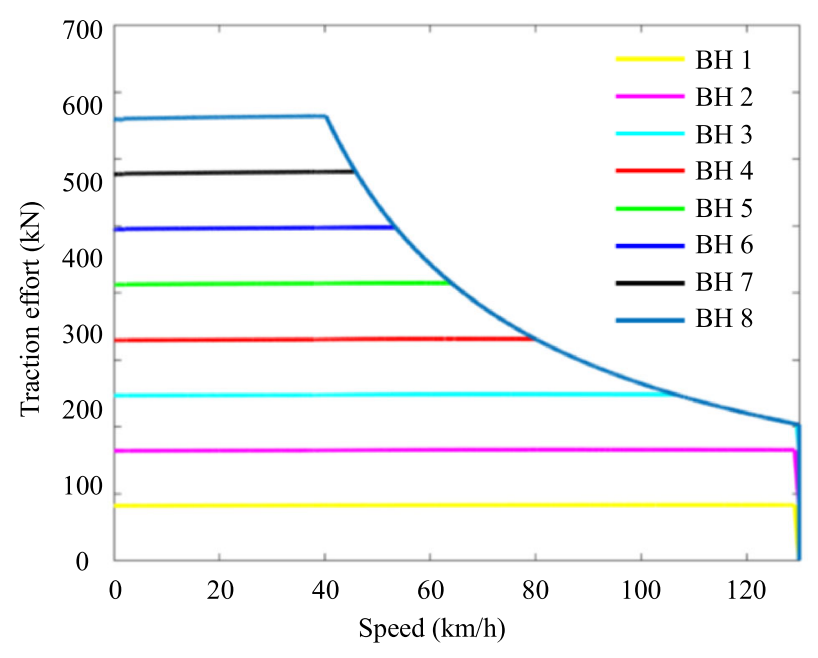

Fig. 6 Dynamic braking characteristics for GT46C-ACe locomotive (BH stands for brake handle) [6]

the case of an empty train, smaller DB values were adequate to keep the speed within the limit. It can be noted that, in normal train operation, air brake and DB would be operating to restrict the speed within the speed board limit. For this study, it is adequate to show that the model reflects the change due to DB application. Recorded track and train operation information can be used in a later study to further quantify the positions of the wayside chargers based on a specific rail network's characteristics.

The simulation was run over the chosen $130 \mathrm{~km}$ track section. The speed and notch inputs define the traction conditions of the locomotive in the MBS. The speed profiles and notch positions obtained from the train simulation were considered as inputs to the MBS of the locomotive. 

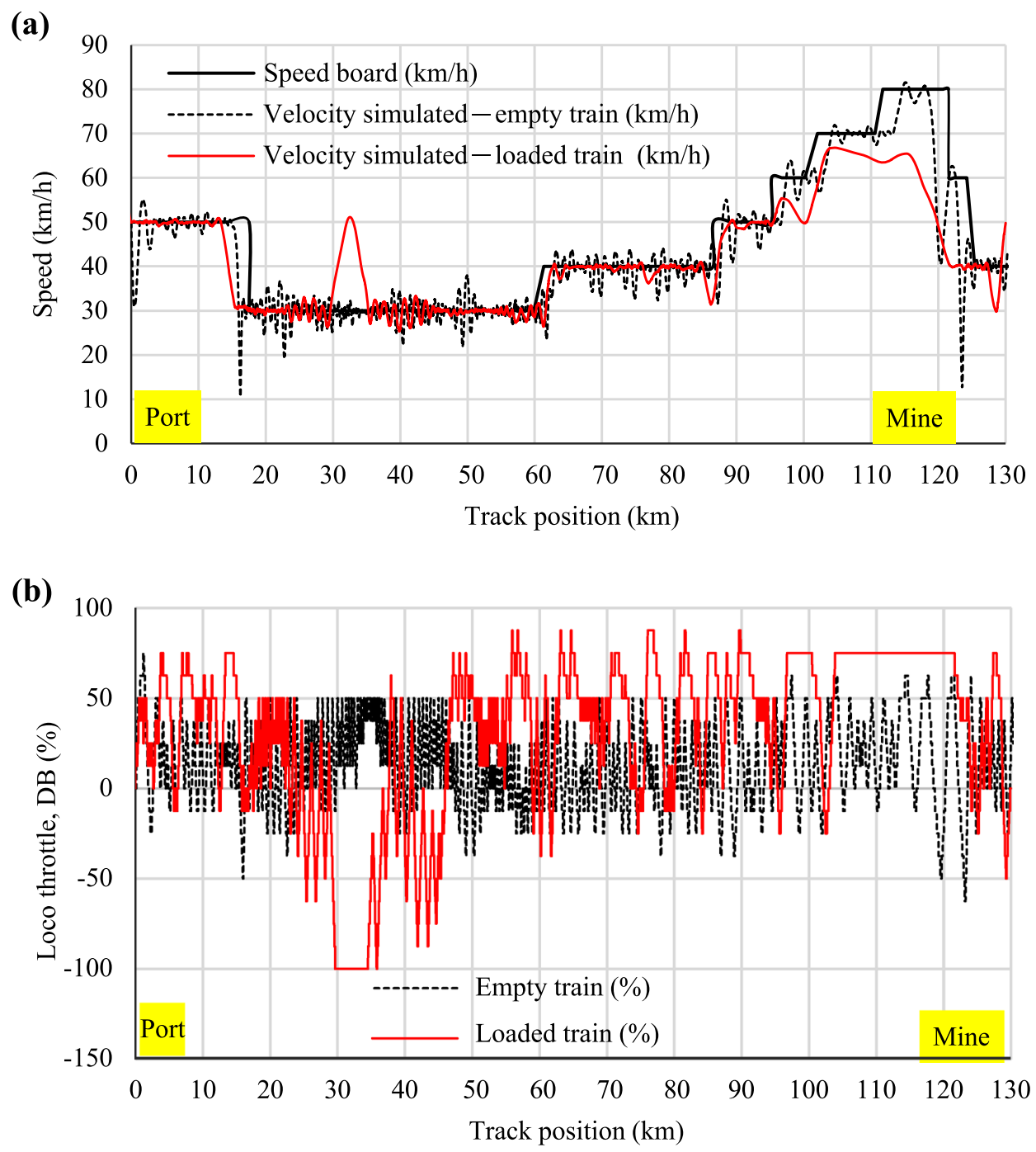

Fig. 7 Speed and locomotive throttle (notch) positions obtained from train simulation in empty train operation: a input speed board data and generated speed profile in longitudinal train simulation; b locomotive throttle and dynamic brake positions obtained from train simulation

\subsection{Modelling of the mechanical part of the hybrid locomotive in MBS software}

The mechanical part of the hybrid locomotive model was developed in GENSYS MBS software [8]. It is assumed that the hybrid locomotive would have similar suspension and mass components as those of the GT46Ace locomotive (Table 1).

A hybrid locomotive has inverters, traction motors, and an ESS (Fig. 3). Three major components of a dieselelectric locomotive, namely a diesel engine, an alternator, and a rectifier can be removed in a hybrid locomotive option and an ESS can be placed into that space. Depending on the purpose of the ESS, the mass of the ESS system can be between $10.3 \mathrm{t}$ and $68.1 \mathrm{t}$ as obtained by theoretical calculations in [9]. For simplicity, it is assumed that the mass of the ESS of the hybrid locomotive would be similar to the combined mass of the diesel engine, alternator, and rectifier of the diesel-electric locomotive. It was assumed that the existing space of a diesel locomotive would be able to accommodate the battery system including the inverter considering the removal of the diesel engine, cooling system, generator, and fuel tanks from the modified version of GT46C-Ace locomotive.

The mechanical part of the rolling stock model of the hybrid locomotive was modelled as similar to the GT46cAce locomotive. The two bogies were bolsterless and consisted of three wheelsets in the Co-Co arrangement. The suspension system has two-stages, primary and secondary. The primary suspension stage contains coil springs and traction rod elements. The secondary suspension contains rubber side bearers (termed as sandwich springs in [10]). Several vertical and lateral hydraulic dampers/shock 
Table 1 Multibody model parameters of the GT46ACe locomotive

\begin{tabular}{|c|c|c|c|}
\hline & Parameter & Unit & Value \\
\hline \multirow[t]{6}{*}{ Dimensions } & Length over couplers & $\mathrm{m}$ & 21 \\
\hline & Nominal coupler height above rail level & $\mathrm{m}$ & 0.89 \\
\hline & $\begin{array}{l}\text { Bogie pivot longitudinal distance from center of } \\
\text { gravity (COG) of car body }\end{array}$ & $\mathrm{m}$ & 6.85 \\
\hline & Bogie semi-wheelbase & $\mathrm{m}$ & 1.9 \\
\hline & New wheel diameter & $\mathrm{m}$ & 1.066 \\
\hline & Total mass & $\mathrm{kg}$ & 136,200 \\
\hline \multirow[t]{6}{*}{ Car body } & CoG height above rail level & $\mathrm{m}$ & 1.93 \\
\hline & Mass & $\mathrm{kg}$ & 92,614 \\
\hline & Moment of inertia, roll & $\mathrm{kg} \cdot \mathrm{m}^{2}$ & 143,503 \\
\hline & Moment of inertia, pitch & $\mathrm{kg} \cdot \mathrm{m}^{2}$ & $3,535,905$ \\
\hline & Moment of inertia, yaw & $\mathrm{kg} \cdot \mathrm{m}^{2}$ & $3,545,078$ \\
\hline & Floor level & $\mathrm{m}$ & 1.5 \\
\hline \multirow[t]{5}{*}{ Bogie frames } & CoG height above rail level & $\mathrm{m}$ & 0.733 \\
\hline & Mass & $\mathrm{Kg}$ & 11,912 \\
\hline & Moment of inertia, roll & $\mathrm{kg} \cdot \mathrm{m}^{2}$ & 5431 \\
\hline & Moment of inertia, pitch & $\mathrm{kg} \cdot \mathrm{m}^{2}$ & 29,507 \\
\hline & Moment of inertia, yaw & $\mathrm{kg} \cdot \mathrm{m}^{2}$ & 34,045 \\
\hline \multirow[t]{5}{*}{ Wheel sets } & CoG height above rail level $=$ new wheel radius & $\mathrm{m}$ & 0.533 \\
\hline & Mass & $\mathrm{Kg}$ & 3,293 \\
\hline & Moment of inertia, roll & $\mathrm{kg} \cdot \mathrm{m}^{2}$ & 1526 \\
\hline & Moment of inertia, pitch & $\mathrm{kg} \cdot \mathrm{m}^{2}$ & 385 \\
\hline & Moment of inertial, yawò & $\mathrm{kg} \cdot \mathrm{m}^{2}$ & 1534 \\
\hline \multirow[t]{4}{*}{ Wheel- rail } & Wheel profile & & New ANZR1 \\
\hline & Rail profile & & New AS60 \\
\hline & Wheel-rail contact & & Modified Fastsim \\
\hline & Coefficient of friction at wheel-rail contact & & Variable \\
\hline \multirow[t]{18}{*}{ Secondary suspension } & Rubber springs & & 4 elements on each bogie \\
\hline & Longitudinal and lateral shear stiffness & $\mathrm{kN} / \mathrm{m}$ & 188.4 \\
\hline & Vertical stiffness & $\mathrm{MN} / \mathrm{m}$ & 7.9 \\
\hline & Traction rods & & 2 elements on each bogie \\
\hline & Stiffness & $\mathrm{MN} / \mathrm{m}$ & 5 \\
\hline & Damping coefficient & $\mathrm{kN} \cdot \mathrm{s} / \mathrm{m}$ & 20 \\
\hline & Yaw viscous dampers & & 2 elements on each bogie \\
\hline & Damping coefficient & $\mathrm{kN} \cdot \mathrm{s}$ & $120 \times 1.24$ \\
\hline & Lateral bump stop between wagon body and bogie frame ${ }^{a}$ & & One element on each bogie frame \\
\hline & Break points & $\mathrm{mm}$ & $30,40,90$ \\
\hline & Stiffness at the breakpoints & $\mathrm{kN} / \mathrm{m}$ & $0,15,2000$ \\
\hline & Vertical bump stop between wagon body and bogie frame ${ }^{a}$ & & Two elements on each bogie frame \\
\hline & Breakpoints & $\mathrm{mm}$ & $25,30,80$ \\
\hline & Stiffness at the breakpoints & $\mathrm{kN} / \mathrm{m}$ & $0,15,2000$ \\
\hline & Lateral viscous damper (asymmetrical) & & Two elements on each bogie frame \\
\hline & Damping coefficient & $\mathrm{kN} \cdot \mathrm{s} / \mathrm{m}$ & 40 \\
\hline & Longitudinal viscous damper (asymmetrical) & & Two elements on each bogie frame \\
\hline & Damping coefficient & $\mathrm{kN} \cdot \mathrm{s} / \mathrm{m}$ & 40 \\
\hline
\end{tabular}


Table 1 continued

\begin{tabular}{|c|c|c|c|}
\hline & Parameter & Unit & Value \\
\hline \multirow[t]{21}{*}{ Primary suspension } & Primary coil springs $b$ & & 6 elements on each bogie \\
\hline & Longitudinal shear stiffness & $\mathrm{MN} / \mathrm{m}$ & $3,45,45$ \\
\hline & Lateral shear stiffness & $\mathrm{MN} / \mathrm{m}$ & $2.5,1.25,1.25$ \\
\hline & Vertical stiffness & $\mathrm{MN} / \mathrm{m}$ & $0.76,0.76,0.76$ \\
\hline & Primary damper ${ }^{\mathrm{b}}$ & & \\
\hline & Longitudinal damping coefficient & $\mathrm{kN} \cdot \mathrm{s} / \mathrm{m}$ & $35,3.5,35$ \\
\hline & Lateral damping coefficient & $\mathrm{kN} \cdot \mathrm{s} / \mathrm{m}$ & $20,20,20$ \\
\hline & Vertical damping coefficient & $\mathrm{kN} \cdot \mathrm{s} / \mathrm{m}$ & $20,20,20$ \\
\hline & Primary longitudinal bump stop & & 3 elements on each bogie \\
\hline & Distance to the hard stop & $\mathrm{mm}$ & 50 \\
\hline & Stiffness at the hard stop & $\mathrm{MN} / \mathrm{m}$ & 40 \\
\hline & Primary lateral bump stop ${ }^{b}$ & & 3 elements on each bogie \\
\hline & Stage 1 distance & $\mathrm{mm}$ & $20,8.75,8.75$ \\
\hline & Stage 2 distance & $\mathrm{mm}$ & $21,20,20$ \\
\hline & Stage 3 distance & $\mathrm{mm}$ & $50,21,20$ \\
\hline & Stage 1 stiffness & $\mathrm{MN} / \mathrm{m}$ & $0,0,0$ \\
\hline & Stage 2 stiffness & $\mathrm{MN} / \mathrm{m}$ & $1,0.028,0.028$ \\
\hline & Stage 3 stiffness & $\mathrm{MN} / \mathrm{m}$ & $2,1,1$ \\
\hline & Vertical bump stop ${ }^{\mathrm{b}}$ & & 6 elements on each bogie \\
\hline & Breakpoints & $\mathrm{mm}$ & 25,50 \\
\hline & Stiffness at breakpoints & $\mathrm{MN} / \mathrm{m}$ & 0,1 \\
\hline
\end{tabular}

${ }^{\mathrm{a}}$ Multi-stage elements

${ }^{\mathrm{b}}$ Three values on each parameter set represent the three wheelsets of a bogie, and the parameter values are expressed for the first, second, and third wheelsets of a bogie

absorbers were installed on both primary and secondary suspensions [10].

A new ANZR1 wheel and new AS60 rail profiles were used in this simulation. Wheel-rail contact was modelled following the modified Fastsim approach published in [11]. The track model was superimposed with track irregularities corresponding to the Federal Railroad Administration (FRA) Class 5 track [12].

The operational condition in the multibody model was taken from the LTS. The speed (Fig. 7a) and notch (Fig. 7b) along the track position as obtained in the LTS have been implemented in the multibody model. The traction behaviour in the MBS model was achieved by applying the equivalent drawbar force through a sky-hook element attached to the locomotive body as also implemented in [13].

\subsubsection{Modelling of the electrical part of the hybrid locomotive in Simulink}

The electrical part of the hybrid locomotive was modelled in a Simulink environment (Fig. 3). The electrical model includes traction and ESS systems which were developed and implemented in previous studies [6, 14]. The traction system model consists of a model for traction motors, a model for the inverter and its controls (based on power electronics), a model for the inverter DC bus (DC storage capacitors and dynamic brake resistors), and a model for an alternator including its excitation and rectifier subsystems [6]. The maximum voltage and current of the DC bus generator were considered as $2650 \mathrm{~V}$ and $1886 \mathrm{~A}$, respectively. Further detail on the modelling of the dieselelectric traction system is available in [15].

The ESS subblock in the Simulink model uses a lookup table to generate voltage input based on speed and notch positions (Fig. 8). The voltage input ranges between 620 and $2600 \mathrm{~V}$ over different notch positions (1-8) and corresponding to various speeds (between 0 and $131 \mathrm{~km} / \mathrm{h}$ ). The voltage is converted to current and then to power corresponding to the DC bus voltage parameter. The power parameter is then converted to energy which is integrated by an integrator to provide the SoC information.

The capacity of the battery unit was considered as $5 \mathrm{MWh}$. Assuming typical energy to weight density of $100 \mathrm{kWh} / \mathrm{t}$, matching that of an automotive lithium battery [14], the $5 \mathrm{MWh}$ battery storage system would have a mass of $50 \mathrm{t}$. 
The battery control options are charging, discharging, and idle roles [14]. During any active notch, the battery discharge mode is active, and the battery seeks to produce a similar voltage to a diesel-electric locomotive. The rate of the discharge depends on notch position and speed.

During an active notch position, the ESS supplies a DC voltage to the traction inverter through a DC link (Fig. 3). Traction inverters provide the required current to the traction motors of wheelsets. The amount of current is restricted by the traction control algorithm that is designed based on slip limits. If DB is applied, the inverters regenerate and return energy to the DC bus, which increases DC bus voltage. The battery system regulates the DC bus voltage and absorbs energy when the battery target voltage is exceeded.

The ESS was designed to discharge at $3100 \mathrm{KW}$ to match the capability of a diesel unit [14]. The charging power $(5000 \mathrm{~kW})$ was made higher than the discharging power to allow the battery to absorb energy from the adjacent diesel unit during dynamic braking [14]. Protection was added in this model to avoid overcharging and deep discharging. Battery charging was limited to $85 \%$, which corresponds to an SoC of $100 \%$ in this model. Discharge rates decrease proportionally when the SoC reaches $5 \%$ until it drops to $0.5 \%$. Charging rates decrease proportionately between the SoCs of $95 \%$ and $99.5 \%$. Power limits (notch and brake power) were set independently for each notch following lookup tables.

\section{Results}

The results of the two trips obtained in the MBS are shown in Figs. 9, 10, 11 and 12, where Lte-Mte stands for difference in calculation of traction force between the LTS and MBS environment. The speed and notch profiles obtained from the LTS simulation were added as inputs to the MBS simulation. The resultant tractive effort from the MBS showed a variation in the tractive effort of up to $70 \mathrm{kN}$ between the LTS and MBS (Figs. 9, 10, 11, 12). It can be noted that the longitudinal train simulation used a constant coefficient of friction and there is no traction/adhesion control in the LTS. The activation of the traction control algorithm in the MBS provides a change in friction condition on wheel-rail contact interface that affects the tractive effort curve; details are available in [16].

Leg 1 of the hypothetical trip 1 started with the loaded train at the fully charged condition $(100 \%$ SoC or $85 \%$ of battery capacity) travelling from the mine at $130 \mathrm{~km}$ to the port at $0 \mathrm{~km}$ (Fig. 9). Following the speed and notch profiles, the electrical model provides the relevant traction forces to the mechanical model.

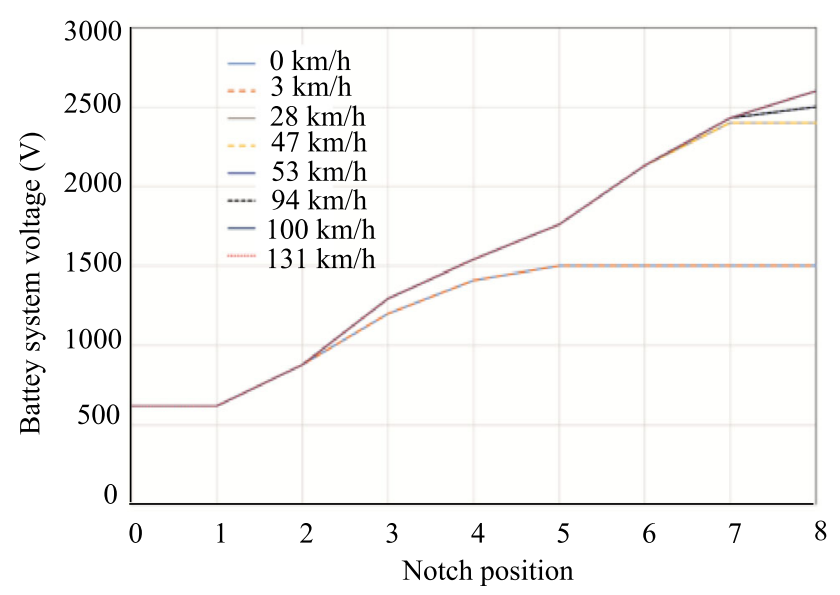

Fig. 8 Battery system voltage in the ESS based on speed and notch positions

It can be noted that the loaded train travels from mine to port, which has a descending grade starting at about the $48 \mathrm{~km}$ mark (Fig. 4). The speed of the loaded train rose sharply to $50 \mathrm{~km} / \mathrm{h}$ on this descending grade and was heavily restricted by the application of dynamic braking to reduce to the $30 \mathrm{~km} / \mathrm{h}$ limit set by the speed board at that position. The SoC of the loaded train had decreased to $54 \%$ at the $47 \mathrm{~km}$ mark near the highest peak point of the track. As another descending grade started, the train needed to limit the speed to that set by the speed board, again requiring application of DB for a long time. The dynamic braking effort of $250 \mathrm{kN}$ and more was applied for about an $8 \mathrm{~km}$ section of track. A medium DB effort $(100-200 \mathrm{kN})$ was applied for a further $20 \mathrm{~km}$ track section which resulted in an increase of $\mathrm{SoC}$ in the model by about $25 \%$. The SoC increased to $79 \%$ at about the $25 \mathrm{~km}$ track mark. As the train travelled further onto a straight track section without any steep gradient, the train started to move with less application of DB force and SoC started to decrease further. At the end of the trip at the $0 \mathrm{~km}$ mark, the $\mathrm{SoC}$ reached $60.65 \%$. Average axle slip was found to be about 5\% when the largest DB force was applied. In zones with less DB, the axle slip was within $2 \%$. The travel time of the loaded train between the mine and port was $196 \mathrm{~min}$.

Leg 2 of trip 1 was simulated using the available SoC at the end of leg 1 of trip 1 which was about $60.65 \%$ (Fig. 10). The empty train condition provides a much lower decrease in SoC at the end of leg 2 of trip 1 of about $12 \%$. It can be noted that the empty train operation requires much less TE (150 kN, Fig. 10) compared to loaded train operation (up to $300 \mathrm{kN}$, Fig. 9) which provided less change in SoC in the empty train condition. The empty train operation also required less DB effort compared to a loaded operation which did not increase SoC similar to that obtained in the loaded condition. 
Changing the starting condition to empty from the port in trip 2 did not change the SoC status much (Figs. 11, 12). In both trips, the $\mathrm{SoC}$ was reduced by about $11 \%$ in empty (Fig. 11) and $41 \%$ in loaded conditions (Fig. 12).

\section{Positioning of wayside charging stations}

As the SoC did not reach below $30 \%$ at any stage of operation on the hypothetical track section, no charging station would be required anywhere along the track. Depending on the operational need, the railway can install a charging station at either the port or the mine. A few situations are added in Fig. 13. The advantage of placing charging stations at the end terminals is that the existing infrastructure can be used to setup charging stations which would reduce infrastructure cost. The other notable feature is that the time for loading and/ or unloading can be used to charge up the battery pack of the hybrid locomotive which would significantly reduce the additional time required for charging operation. In the case of charging at the terminals, the hybrid locomotive needs to be disengaged from the train and placed in the charging station. It is anticipated that the diesel locomotive on the train would be adequate to shunt the train during loading and unloading operations. If required, a shunting locomotive can be added for the loading and unloading operations.

\section{Discussion}

In this study, the hybrid locomotive started at the SoC level of $100 \%$ (corresponding to $85 \%$ battery charge level) which is $15 \%$ above the recommended hybrid operation limit as mentioned in [1]. The charging limits are applied to protect the batteries from overcharging in case of the sudden application of a large current surge. It can be noted that the power surge protector circuit is available in roadside charging stations for automobiles. Availability of power surge protectors would increase the SoC limit of hybrid locomotives. Availability of more SoC would mean that hybrid locomotive would travel a longer distance at a single charge.

The results show that the rate of discharge does not depend on the starting SoC of a trip. The loaded cases resulted in a $40 \%$ reduction in SoC in both cases when starting SoCs were $100 \%$ and $89 \%$. The empty cases resulted in an $11 \%$ reduction in SoC regardless of starting SoCs of $100 \%$ and $60 \%$. Considering the $15 \%$ reserve used in the modelling of the battery in this paper, the lowest SoC recorded as $49 \%$ would represent a battery charge of $34 \%$. The corresponding battery charge for the trip used in this paper can be considered as 34\%-85\%. It would be possible that the chosen trip could be started at a further $10 \%$ lower charge of the batteries, i.e. $75 \%$, to limit the operation to between $25 \%$ and $75 \%$ which are within the recommended hybrid range of $20 \%-80 \%$ as per [1].
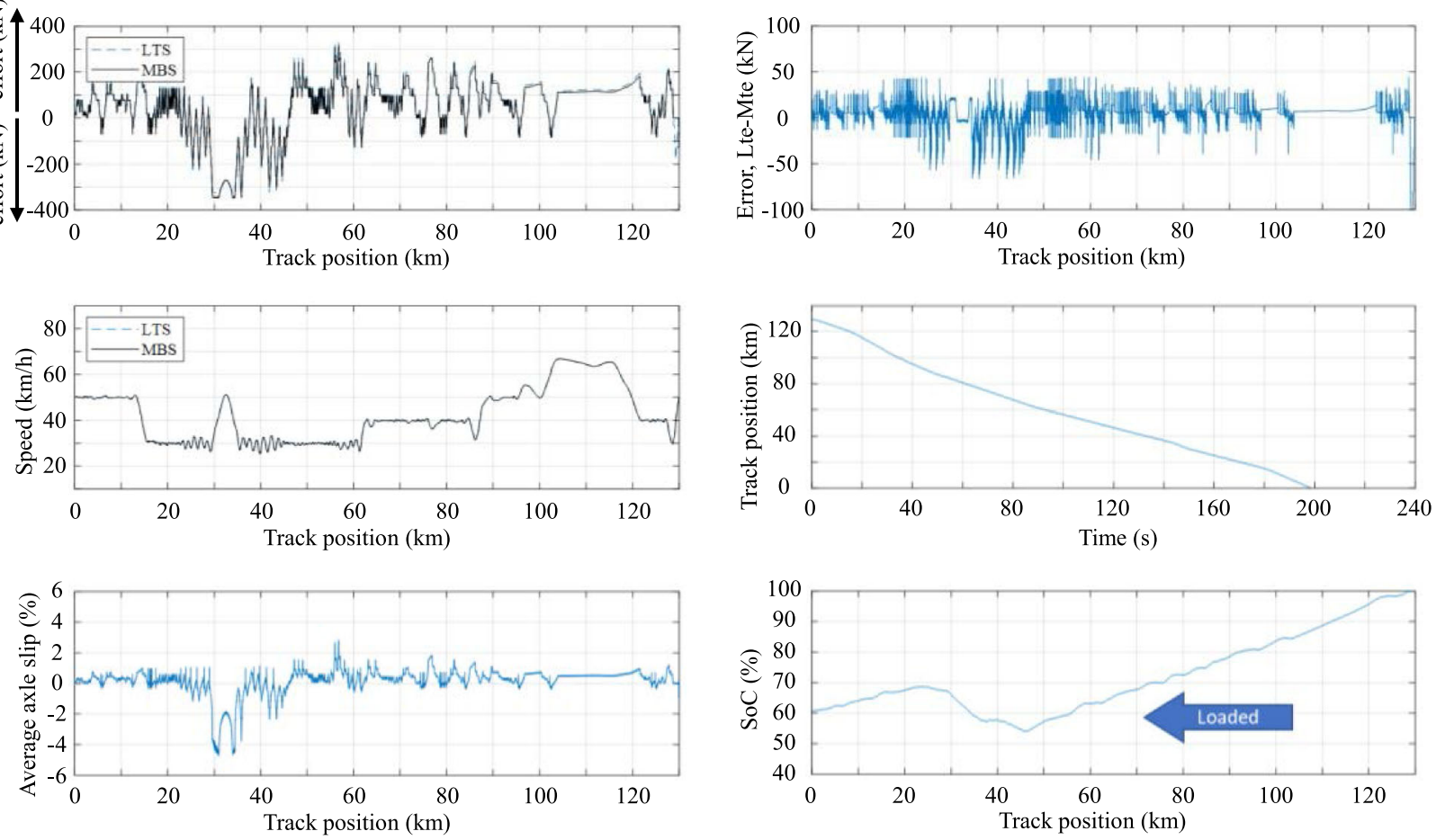

Fig. 9 Trip 1, leg 1, and the loaded train from mine to port (starting at the fully charged condition) 

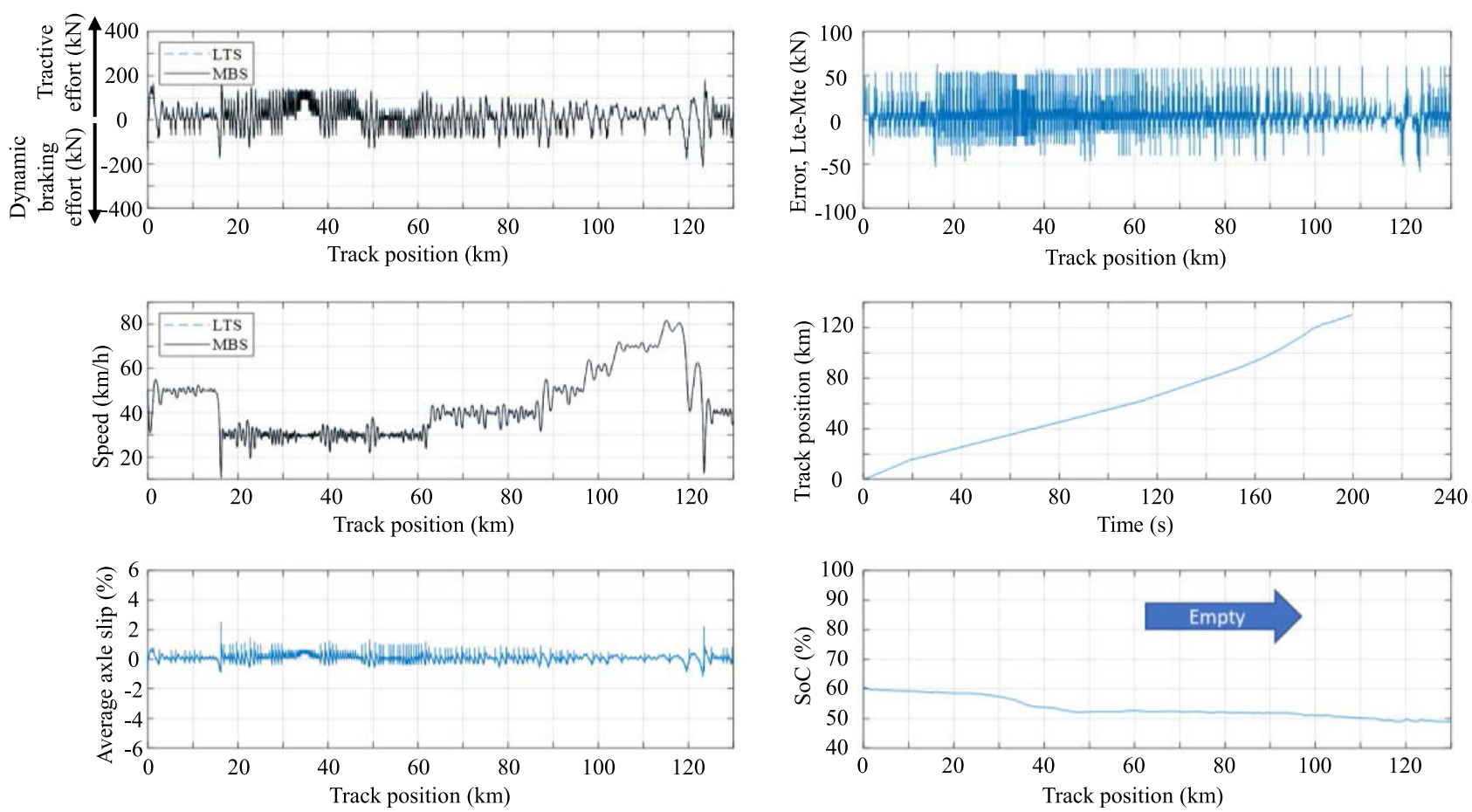

Fig. 10 Trip 1, leg 2, and the empty train from port to mine (starting with the charge remaining after completing leg 1)
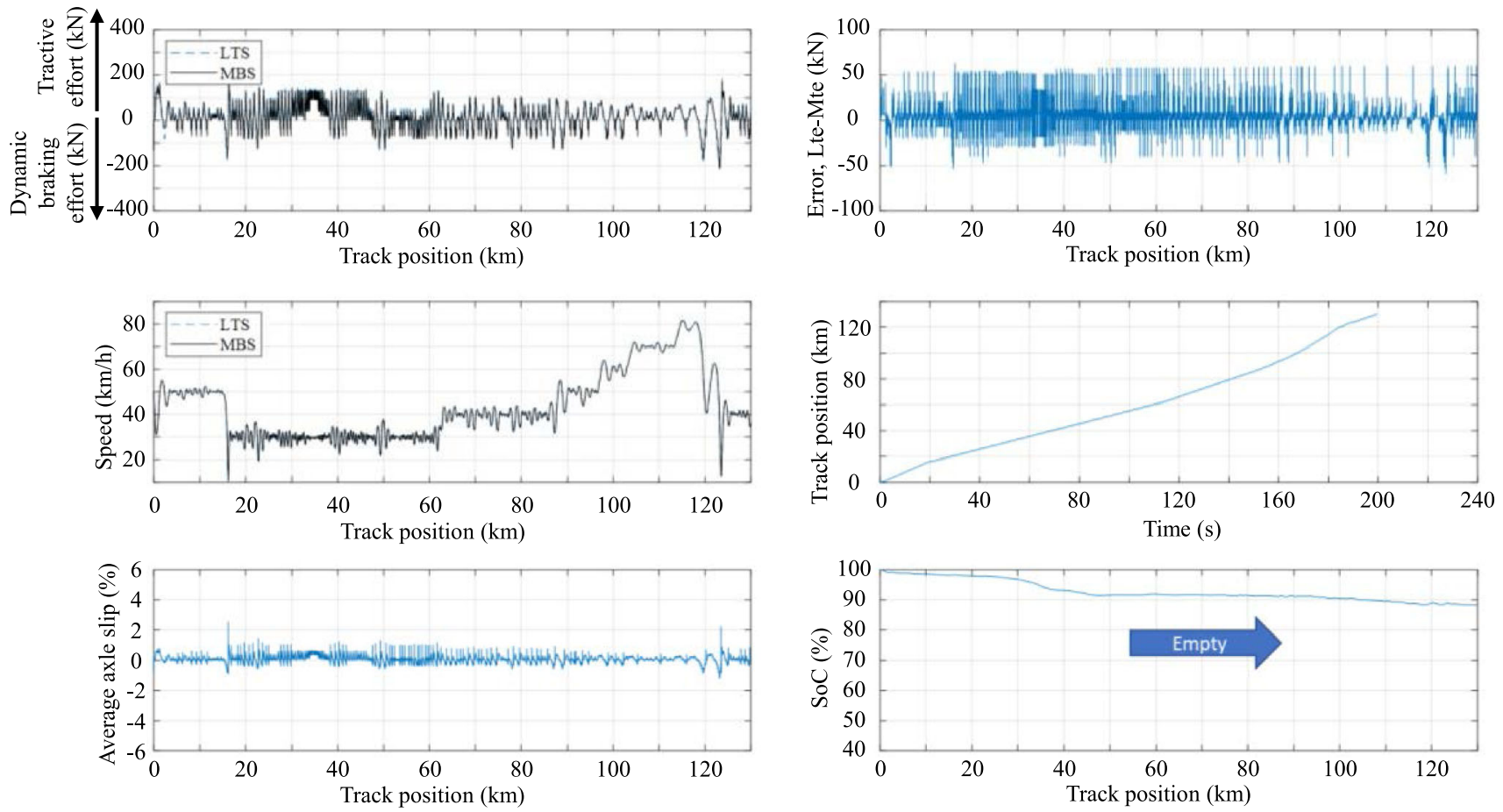

Fig. 11 Trip 2, leg 1, and the empty train from port to mine (starting at the fully charged condition)

While only the driving operation has been considered in this simulation as the means of discharging the battery, it should be noted that several factors could influence the SoC of batteries including temperature, the efficiency of the battery, the material of the battery, etc., and further details are available in [1, 17]. Faster charging would result in a shorter battery life [17], which would discourage the 

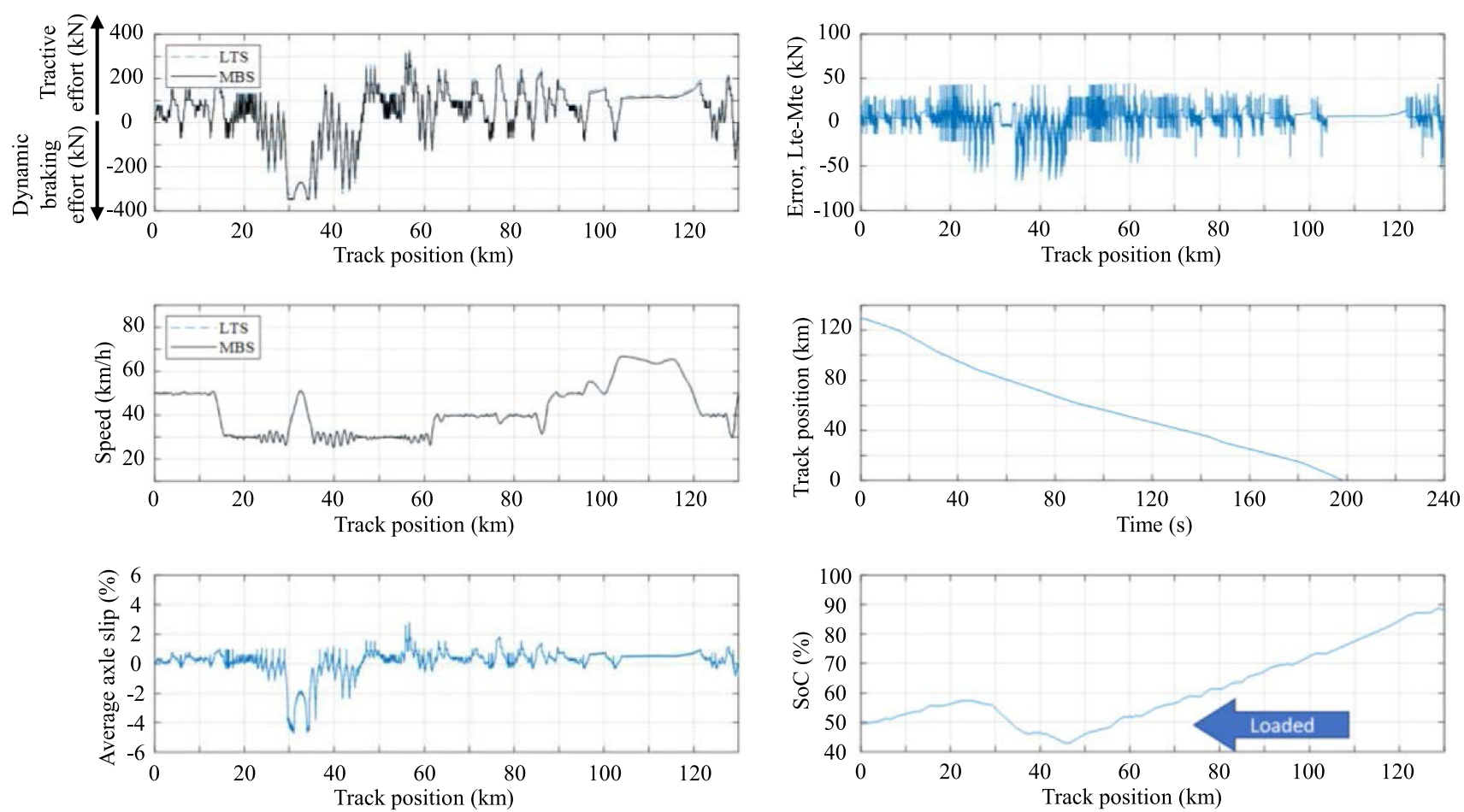

Fig. 12 Trip 2, leg 2, and the loaded train from mine to port (starting with the charge remaining after completing leg 1)

faster charging option unless the cost of the battery is less than the cost of idling time of a train.

A wayside charging station would require getting energy from the power grid network, which would make the demand for power systems high. A fast charging would require a large current to be drawn in a short time which may put additional stress on the power grid network. To compensate for the need for high current during fast charging, a charging station can be equipped with an ESS to supplement the charging requirement; such a method has been discussed in [18]. The charging station could also be of a hybrid type to provide an auxiliary power source to the charging station.

A simplified ESS modelling approach has been used in this paper to demonstrate a method to establish the required positions of wayside charging stations based on SoC information of a train. The battery model used in this study follows lookup tables to relate the notch and voltage parameters. The actual characteristics of the battery would influence the design of a hybrid locomotive. The cycle life of batteries depends on various factors such as nature of use, temperature, design materials, charge and discharge current, excessive charge/discharge, and storage [17]. In hybrid locomotive applications, it is recommended to use the SoC level of $50 \%$ to protect from overcurrent surge during DB. Depth of discharge (DOD) indicates how much discharge from the maximum allowable charged condition is allowed. It is well known that battery cycle life increases if the DOD is less, i.e. frequent charging can be provided. Battery manufacturers recommend a DOD for the battery which is usually $80 \%$ DOD or less. It is also recommended that the DOD range is kept close to the central part of the capacity range of a battery, i.e. at the $50 \%$ SoC level. However, for train applications, the time for the charging operation needs to be planned to avoid delay in transportation. For dual-mode operation, it is desirable that the train would travel a longer distance after a single charge.

The case study chosen in this paper was primarily aimed to show the method. The driving strategy, in particular the application of DB, would have some effect on the timing of recharging the battery system in the locomotive. It is anticipated that a typical track route with recorded DB characteristics would be useful to better correlate the positions of wayside charging stations.

The positioning of the wayside charging station should also need to consider the service life performance of a battery unit. The influence of operation condition, ageing, temperature, etc., on available battery power, charging, and discharging characteristics need to be considered when assessing the positioning of the charging station. The simulation tool developed in this study could be used for further analysis of changing battery conditions to assess the positioning of a wayside charging station considering multiple variables. 


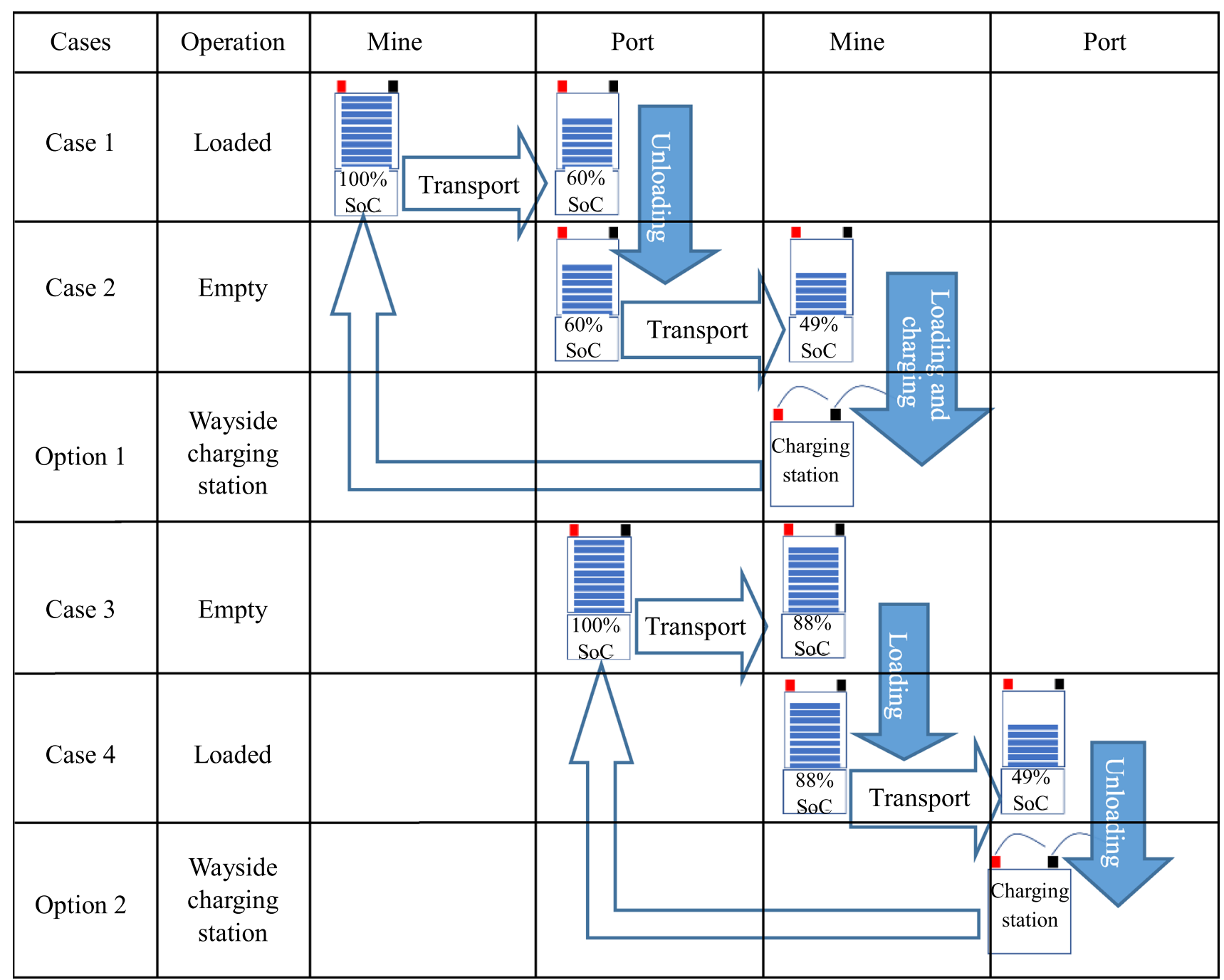

Fig. 13 Positions of wayside charging stations

\section{Conclusion}

A method has been developed to demonstrate the application of simulation tools to find a suitable location for wayside charging stations for a hybrid locomotive on a track network. The method has been applied to hypothetical track and train configurations on a typical port to mine operation. The result show that the simulation tool is able to evaluate the $\mathrm{SoC}$ of the hybrid locomotive along the track which can be used to evaluate the positions of charging stations along the route.

Open Access This article is licensed under a Creative Commons Attribution 4.0 International License, which permits use, sharing, adaptation, distribution and reproduction in any medium or format, as long as you give appropriate credit to the original author(s) and the source, provide a link to the Creative Commons licence, and indicate if changes were made. The images or other third party material in this article are included in the article's Creative Commons licence, unless indicated otherwise in a credit line to the material. If material is not included in the article's Creative Commons licence and your intended use is not permitted by statutory regulation or exceeds the permitted use, you will need to obtain permission directly from the copyright holder. To view a copy of this licence, visit http://creativecommons. org/licenses/by/4.0/.

\section{References}

1. Nelson RF (2000) Power requirements for batteries in hybrid electric vehicles. J Power Sources 91(1):2-26

2. Lawson LJ, Cook LM (1979) Wayslde energy storage study, volume IV - dual mode locomotive: preliminary design study. U.S. Department of Transportation, Federal Railroad Administration

3. Battery University (2020) BU-401a: fast and ultra-fast chargers. https://batteryuniversity.com/learn/article/ultra_fast_chargers

4. Ahmed S, Bloom I, Jansen AN, Tanim T, Dufek EJ, Pesaran A et al (2017) Enabling fast charging - a battery technology gap assessment. J Power Sources 367:250-262

5. Bosomworth C, Spiryagin M, Alahakoon S, Cole C (2017) The effect of vehicle dynamics on rail foot flaw detection. In: 
Proceedings of the 25th international symposium on dynamics of vehicles on roads and tracks (IAVSD 2017), Rockhampton, Australia

6. Spiryagin M, Wu Q, Bosomworth C, Cole C, Wolfs P, Hayman $\mathrm{M}$, et al (2019) Understanding the impact of high traction hybrid locomotive designs on heavy haul train performance. In: the AusRAIL PLUS Conference, Sydney, 3-5 December 2019

7. Spiryagin M, Persson I, Wu Q, Bosomworth C, Wolfs P, Cole C (2019) A co-simulation approach for heavy haul long distance locomotive-track simulation studies. Veh Syst Dyn 57(9): $1363-1380$

8. DEsolver AB (2020) Gensys.1908. http://gensys.se/news/rel. 1908/index.html\#

9. Sun Y, Cole C, Spiryagin M, Godber T, Hames S, Rasul M (2013) Conceptual designs of hybrid locomotives for application as heavy haul trains on typical track lines. Proc Inst Mech Eng Part F J Rail Rapid Transit 227(5):439-452

10. Spiryagin M, Wolfs P, Cole C, Spiryagin V, Sun Y, McSweeney $\mathrm{T}$ (2017) Design and simulation of heavy haul locomotives. CRC Press, Boca Raton

11. Spiryagin M, Polach O, Cole C (2013) Creep force modelling for rail traction vehicles based on the Fastsim algorithm. Veh Syst Dyn 51(11):1765-1783

12. Federal Railroad Administration (2017) Track and rail and infrastructure integrity compliance manual, volume II Track safety standards, Chapter 1: track safety standards, classes 1 through 5. Federal Railroad Administration

13. Spiryagin M, Wolfs P, Wu Q, Cole C, McSweeney T, Bosomworth C (2020) Rapid charging energy storage system for a hybrid freight locomotive. In: Proceedings of the 2020 ASME joint rail conference, St. Louis, MO, USA

14. Spiryagin M, Wu Q, Wolfs P, Sun Y, Cole C (2018) Comparison of locomotive energy storage systems for heavy-haul operation. Int J Rail Transp 6(1):1-15

15. Spiryagin M, Wolfs P, Szanto F, Cole C (2015) Simplified and advanced modelling of traction control systems of heavy-haul locomotives. Veh Syst Dyn 53(5):672-691

16. Cole C, Spiryagin M, Wu Q, Sun Y (2017) Modelling, simulation and applications of longitudinal train dynamics. Veh Syst Dyn 55(10):1498-1571

17. Brady M (2017) Assessment of battery technology for rail propulsion application, DOT/FRA/ORD-17/12. U.S. Department of Transportation, Federal Railroad Administration

18. Li H, Peng J, Liu W, Huang Z (2015) Stationary charging station design for sustainable urban rail systems: a case study at Zhuzhou Electric Locomotive Co., China. Sustainability 7(1):465-481 